\title{
Physiological and psychophysiological indicators in the diagnosis of occupational maladaptation of doctors from oncology hospital
}

\author{
Физиологические и психофизиологические показатели в диагностике \\ профессиональной дезадаптации врачей онкологического стационара
}

Received: February 1, 2021

\section{Abstract}

Objectives: To study the development of professional deformity in oncological hospital doctors under the influence of professional activity factors. To consider the issues of professional adaptation of medical workers from the perspective of their development of psychoemotional burnout in combination with the problem of physiological and psychophysiological aspects of professional maladaptation. Methods: The analysis of the features of maladaptive reactions of the cardiovascular system of oncological hospital doctors that occur in the course of their professional activities is based on the analysis of changes in three groups of indicators of adaptive response of the cardiovascular system of oncologists, characteristics of blood pressure, heart activity indicators, and the state of peripheral vascular tone. Calculations of the values of psychophysiological indices that integrally characterize the functional state of their body are made. All of the doctors participating in the survey gave informed consent on the acquisition and processing of data. Results: It was found that a significant number $(75 \%)$ of the tested oncologists have reduced
Accepted: March 20, 2021

Written by:

Konstantin Zasyadko ${ }^{14}$ https://orcid.org/0000-0001-6688-1910

Sergey Shinkarev ${ }^{15}$ https://orcid.org/0000-0003-0844-4733

Oleg Dankovtsev ${ }^{16}$ https://orcid.org/0000-0002-4814-4359

Lilia Tafintseva ${ }^{17}$ https://orcid.org/0000-0001-7729-7656

Svetlana Maskalyanova ${ }^{18}$ https://orcid.org/0000-0002-2744-7190

\begin{abstract}
Аннотация
Задачи: изучить развитие профессиональной деформации у врачей онкологических стационаров под влиянием факторов профессиональной деятельности. Рассмотреть вопросы профессиональной адаптации медицинских работников с точки зрения развития у них психоэмоционального выгорания в сочетании с проблемой физиологических и психофизиологических аспектов профессиональной дезадаптации. Методы. Анализ особенностей дезадаптивных реакций сердечно-сосудистой системы врачей онкологических стационаров, возникающих в процессе их профессиональной деятельности, основан на анализе изменений следующих групп показателей: адаптивного ответа сердечно-сосудистой системы онкологов, характеристик артериального давления, показателей сердечной деятельности и состояния тонуса периферических сосудов. Выполнены расчеты значений психофизиологических показателей, интегрально характеризующих функциональное состояние их организма. У всех врачей, участвовавших в опросе, было получено информированное согласие на сбор и
\end{abstract}

\footnotetext{
${ }^{14}$ Prof., DSc, Lipetsk of State Pedagogical University, Russia

15 Prof., DSc, Lipetsk of State Pedagogical University, Russia

${ }^{16}$ Docent, PhD, Lipetsk of State Pedagogical University, Russia.

${ }^{17}$ Docent, PhD, Lipetsk of State Pedagogical University, Russia.

18 Docent, PhD, Lipetsk of State Pedagogical University, Russia.
} 
adaptive capabilities of the circulatory system. A significant number of individuals with low stroke $(40 \%)$ and minute blood volume $(30 \%)$ were identified. In most cases (up to $68.4 \%$ ) the examined specialists of the oncological hospital are in a state of impaired professional adaptation according to psychophysiological criteria. Conclusions: It is proposed to use the physiological and psychophysiological indicators used in the study as psychophysiological correlates of the formation and development of professional maladaptation in doctors of different specialties, as well as to control the dynamics of their condition during medical and social rehabilitation of medical institutions.

Key Words: adults, cancer, oncologists, professional adaptation, psycho-oncology, rehabilitation, symptoms. обработку данных. Результаты. Установлено, что у значительного числа (75\%) опрошенных онкологов снижены адаптивные возможности кровеносной системы. Выявлено значительное количество лиц с низкими ударным объемом (40\%) и минутным объемом крови (30\%). В большинстве случаев (до $68,4 \%$ ) обследованные специалисты онкологической больницы находятся в состоянии нарушенной профессиональной адаптации по психофизиологическим критериям. Выводы: Предложено использовать в исследовании физиологические и психофизиологические показатели в качестве коррелятов формирования и развития профессиональной дезадаптации у врачей разных специальностей, а также для контроля динамики их состояния при медико-социальной реабилитации.

Ключевые слова: взрослые, рак, онкологи, профессиональная адаптация, психоонкология, реабилитация, симптомы.

\section{Introduction}

The term "emotional burnout" was introduced by H.J. Freudenberger (1974) to characterize the psychological state of healthy people who intensively and closely communicate with clients, patients in an emotionally rich atmosphere when providing professional care. The main predisposing factor for emotional burnout is duration of work and excessive workload in situations of tense interpersonal relationships. In this regard, the syndrome of emotional burnout is characteristic of the communicative professions representatives, primarily doctors and medical personnel of the population (Gômez-Urquiza et al., 2016; Edwards et al., 2002).

Burnout is a dysfunctional health state that occurs in employees under the influence of prolonged psychoemotional stress (Maslach et al., 2018; Gardner et al., 2019). It is a response to long-term professional stresses arising in interpersonal communications, characterized by emotional exhaustion, decrease in the effectiveness of professional activity, devaluation of labor and decrease in the significance of one's own success. We are talking about emotional burnout, i.e. a dynamic process that is implemented in stages, in full accordance with the mechanism of stress progression (Yates, 2020).

As an occupational stress, burnout includes both psychological and psychosomatic aspects (Consoli 2015; Toker et al., 2012). This is why it can lead either to a decrease in the number of doctors who are supposed to retire from their professional occupation earlier, or to a reduction in their working hours, while the need for this profession is growing in developed countries due to aging of the population. Particularly high level of stress, one of the highest rates of dissatisfaction with the profession and the frequency of cases of depression is observed precisely in doctors. High rates of suicide among doctors, especially oncologists are witnessed (Corrigan et al., 2019; Medscape, 2020; Murali and Banerjee, 2018). All this forces the need to study professional stress and emotional burnout among doctors (Akman et al., 2016).

In the literature review, the authors highlight the main idea: burnout fundamentally destroys a person's mental health. Research shows that clinical intervention can actually impair a person's professional performance. Therefore, the issue of rehabilitation of working doctors, interdisciplinary measures aimed at preservation and increase of the working capacity of employees are of particular importance. The authors believe that the methods that help to assess circulatory dynamics among oncologists serve the ultimate goal of the study - to understand the processes and causes of professional maladaptation, as well as to develop methods of patient rehabilitation. The results of the study show that, indeed, professional burnout leads either to local or general disturbances in hemodynamic parameters; these changes can be both a cause and a consequence of disturbed adaptation processes occurring in the body. All this makes it difficult to identify 
and treat burnout, which, moreover, as the study shows, disrupts general physical performance and the state of the cardiovascular system of a person. The article discusses the problem of the borderline state of a sick organism between norm and pathology. As a result, the recommendations propose means to increase the psycho-physiological and physiological indicators of the professional adaptation of patients.

Thus the aim of the research is to study the characteristics of the reaction of the cardiovascular system of the body of doctors of an oncological hospital in the process of their adaptation to the conditions of professional activity based on the study of indicators of its tone and indices that integrally characterize the functional state of their body.

\section{Theoretical Framework or Literature Review}

The work of a doctor in an oncological hospital is characterized by high moral and social responsibility, permanent stressful interpersonal communication with colleagues and patients experiencing a high level of both physiological and psychological suffering (Murali and Banerjee, 2019; Raphael et al., 2019; Yates and Samuel, 2019). This naturally results in a high level of stress of the adaptive capabilities of oncologists and is accompanied by a certain increase in the risk of developing professional adaptation disorders in them, the manifestations of which in the socio-psychological sphere are professional burnout syndrome and some other negative manifestations such as social adaptation disorders, a decrease in the level of neuropsychic and general health (Berniell and Bietenbeck, 2020; Britt et al., 2017; Fernández-Sánchez et al., 2018; Harma, 2003; Lee et al., 2008; Tilett, 2003; Van der Hulst, 2003; Williams, 2002).

Identification at early stages of development and preventive prophylaxis of professional maladaptation to optimize work behavior, better tolerance of workloads by doctors and improve the quality of qualified treatment of patients in an oncological hospital. This requires a deeper study of the causes of stress (stressors) in the practice of professional workers involved in the doctor-patient format (Black et al., 2015; Maslach et al., 2001; Swetz et al., 2009; Tilett, 2003). Consequently, the study of the characteristics of professional stress and the influence of its factors on the health of a professional doctor is of paramount importance in the context of today's society, which is the subject of this study (Zasyadko, 2019). The above mentioned determines the relevance of the research topic aimed at studying the physiological and psychophysiological aspects of professional maladaptation of doctors of an oncological hospital.

A multilevel functional system of adaptation of a professional, as you know, is formed through the simultaneous impact and mutual influence of psychological and psychophysiological components of the adaptive responding reaction. The scope of changes, which is determined by each of these components, depends on the ratio of the main goals of the adaptation process - preservation of homeostasis and implementation of the tasks of activity at a proper level (Baevsky and Berseneva, 2011; Baevsky and Berseneva, 2017; White, 2002).

These two areas can be reconciled only by an integrated, systematic approach to research, which will allow to highlight the main characteristic features that combine the psychological, psychophysiological and medico-social levels of the adaptation process, which determine its success: the general psychological state and the level of psychophysiological reserves of a professional (Baevsky et al., 2015; Williams, 2002).

Following this principle led to the substantiation of the basic role of the psychophysiological characteristics of the main life-supporting systems of the subject's body, primarily the cardiovascular system, in the direction of ensuring the stability and continuity of the adaptation process (Baevsky and Berseneva, 2011; Tilett, 2003). However, the methods currently used by many researchers for assessing violations of the socio - psychological adaptation of doctors based on the diagnosis of emotional - psychological burnout syndrome are mainly analyzed without regard to the characteristics of physiological and psychophysiological changes in the body, which creates difficulties in the interpretation of the research results and not always complete presentation of the whole picture of the processes taking place in the body of the tested professionals (Banerjee, 2019; Crane et al., 2020; Hariharan and Griffin, 2019; Stucky et al., 2009; Van Dam et al., 2015; Raphael et al., 2019). 


\section{Methodology}

Registration and calculation of the main hemodynamic parameters were carried out using the method of volumetric compression oscillography using the software and hardware complex APKO-8 RIC. Three groups of indicators of the cardiovascular system were identified. The first is the indicators characterizing systemic hemodynamics, such as the results of measuring the blood pressure itself: systolic, indicating the propulsive activity of the heart; diastolic, reflecting the state of blood flow in the precapillary bed; average hemodynamic, resulting in all values during one cardiac cycle and characterizing the tonic tension of the vessels. The second group of indicators made it possible to assess cardiac activity - heart rate (HR), stroke volume (SV) and and cardiac output (CO) of blood. The latter refer to the main indicators of hemodynamics, which comprehensively characterize the intensity of the functioning of the circulatory system as a whole. The third group of indicators - vascular - made it possible to determine the state of vessels of the elastic and muscular type according to the data of pulse wave velocity (PWV) and total peripheral vascular resistance (PVR). PWV reflects the state of the tone of large vessels; PVR characterizes the degree of patency of the precapillary bed and tonic tension of arterioles, which also makes it possible to judge the adequacy of their response to changes in the minute volume of circulation (Baevsky et al., 2015).

Based on the comparison of the data of three groups of indicators obtained in the study, the type of hemodynamic regulation (hypokinetic, eukinetic or hyperkinetic) of the subject's circulatory system was determined (Baevsky and Berseneva, 2017).

The obtained data made it possible not only to analyze and process the basic clinical and physiological information, but also to perform an integral level assessment of its functioning by means of an objective statistically reliable weighted assessment of complex criteria. Several indices that showed quite well in clinical-physiological and professional studies were used as integral indicators of the adaptation level dynamics, which comprehensively characterize the functional state of the subject: the functional change index of (FCI) according to R.M. Baevsky; the physical condition index (PCI), the tested stress index (TSI), the Myznikov index (Myznikov et al., 2008), the Robinson index (Robinson, 1967).

The FCI according to R.M. Baevsky was calculated using the formula FCI $=0.011 \times \mathrm{HR}+0.014 \mathrm{xSD}+$ $0.008 \mathrm{xDP}+0.014 \mathrm{xA}+0.009 \mathrm{xW}-0.009 \mathrm{xH}-0.27$, where HR is the heart rate per minute; $\mathrm{SP}-$ systolic pressure, mm Hg; DP - diastolic pressure, mm Hg; A - age, years; $\mathrm{W}$ - weight, $\mathrm{kg}$; $\mathrm{H}$ - height, $\mathrm{cm}$. According to the standard value, AP $<2.11$, within the range of 2.11-3.20 - tension of adaptation mechanisms, within the range 3.21-4.30 - unsatisfactory adaptation, AP> 4.1 - adaptation mechanisms failure. The physical condition index (PCI) was determined according to the formula of the regression equation: $\mathrm{PCI}=(700-3 \mathrm{xHR}-2.5 \mathrm{xMAP}-2.7 \mathrm{xA}+0.28 \mathrm{xW}) /(350-2.6 \mathrm{xA}+0.21 \mathrm{xH})$, where: $\mathrm{MAP}=\mathrm{ADP}$ + 1/3 PBP; PBP = SBP-DBP; MAP - mean arterial pressure $(\mathrm{mm} \mathrm{Hg})$; DBP - diastolic blood pressure $(\mathrm{mm}$ $\mathrm{Hg}$ ); SBP - systolic blood pressure ( $\mathrm{mm} \mathrm{Hg}$ ); PBP - pulse blood pressure ( $\mathrm{mm} \mathrm{Hg}$ ); MAP - mean arterial pressure (mm Hg); A - age (years completed); W - body weight $(\mathrm{kg}) ; \mathrm{H}$ - standing height $(\mathrm{cm})$. The subjects had one of five levels of physical condition: high (>0.826); above the mean (from 0.676 to 0.825 ) mean - from 0.526 to 0.675 ; below the mean - (from 0.376 to 0.525$)$ and low $(<0.375)$.

The level of the tested stress indicating a degree of general stress, which the subject had, was determined using the formula: TSI = HR x PBP x M1/3x 0.000126, where HR is a number of heartbeats (pulse rate) per minute; PBP - pulse blood pressure, mm Hg. PBP = SBP-DBP. W - body weight (kg). According to the standard value, TSI is not more than 1.5 c.u., 1.5-2.0 c.u. - moderate stress, more than 2.0 c.u. - severe stress. These indicators characterize the relationship between cardiac-hemodynamic (HR, SBP, DBP) and structural-metabolic (H, BW) homeostasis. In this case, the indicator of age plays the role of a feedback element between these homeostasises.

The decrease in the adaptive body capabilities under the conditions of professional activity was determined using an integral criterion, namely the Myznikov index (MI) to be calculated using the main hemodynamic parameters according to the formula: $\mathrm{MI}=\mathrm{SBP} / \mathrm{DBP} \times \mathrm{HR}$, where HR is a heart rate, $\mathrm{DBP}$ is the diastolic blood pressure $(\mathrm{mm} \mathrm{Hg})$; SBP - systolic blood pressure $(\mathrm{mm} \mathrm{Hg})$. According to the results of MI determination, the subjects are distributed according to five levels of functional activity of the body: extremely low or hyporeaction (up to 64.34), below the mean $(64.35-82.55$ ), average or optimal $(82.56-118.94)$ above the mean or functional reactivation $(118.94-137.14)$, and extremely high, hyper response or maladaptation (137.15 and over). 
The Robinson index or the double product index is one of the criteria for the functional state of the cardiovascular system, which indirectly reflects the load on the myocardium and its oxygen demand, was determined according to the formula RI $=\mathrm{HR} \times \mathrm{SBP} / 100$ (c.u.). According to the RI level, the level of subject's body adaptation was characterized as high (less than 69 c.u.), above the mean ( $70-84$ c.u.), mean values ( 85 - 95 c.u.); below the mean $(96-110$ c.u.) and low (more than 110 c.u.) A low rating of the Robinson index (RI) indicates an impaired regulation of the cardiovascular system.

32 doctors of the oncological hospital with at least 5 years of work experience in the oncological dispensary were involved in the research. The age of the subjects ranged from 28 to 57 years (an average age is $45 \pm$ 4 years). All participants expressed their voluntary participation in the investigation.

\section{Results and discussion}

The results for analyzing the measurement of blood pressure indicators (the first group of indicators) in the subjects in relation to the proper values (in \%) are shown in Fig. 1.

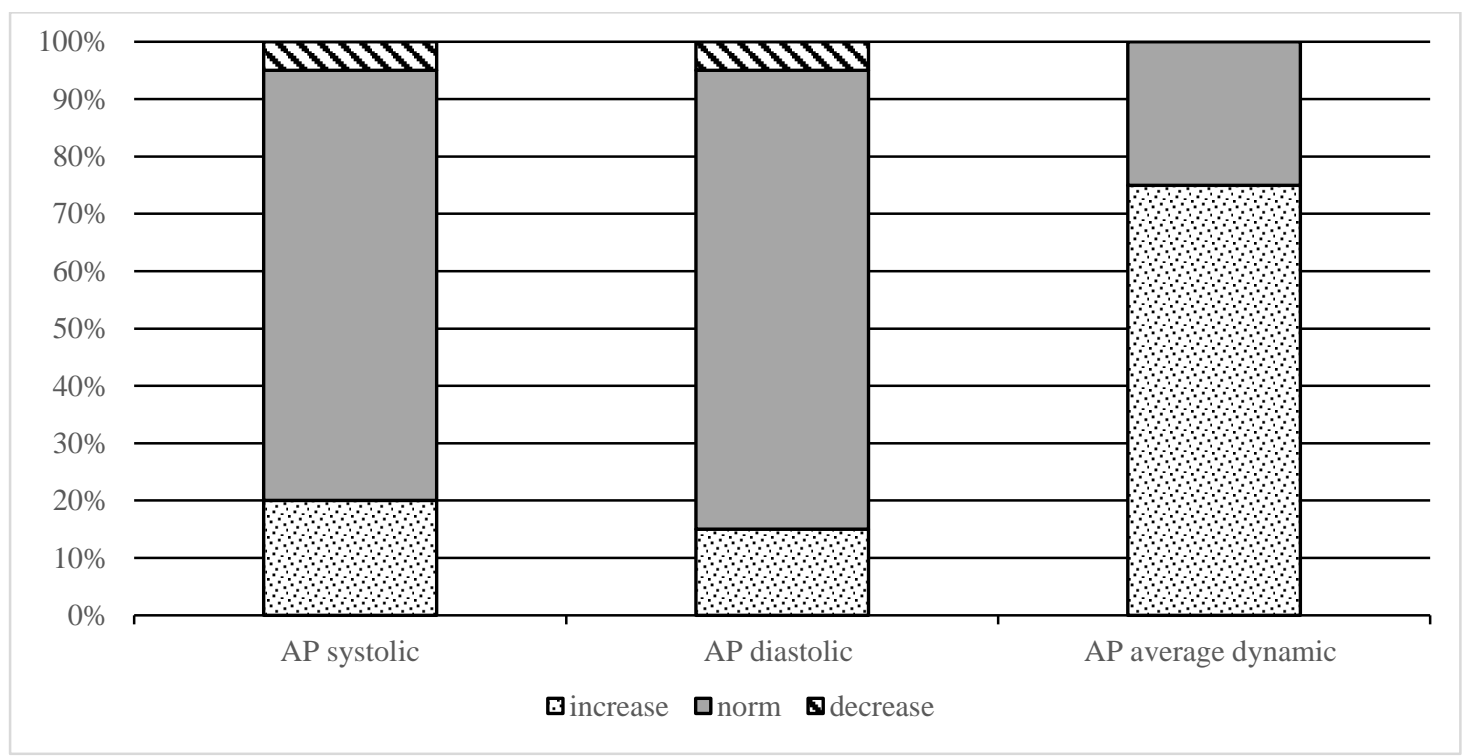

Figure 1. Subjects' blood pressure indicators in relation to the proper values, $\%$

Pursuant to the data in Fig. 1, and systolic and diastolic blood pressure in each of the tested groups generally correspond to the proper values ( $75 \%$ and $80 \%$ of doctors, respectively). The proportion of persons with symptoms of hypertension was $20 \%$ in cases of systolic blood pressure and $15 \%$ for diastolic one. Hypotension in relation to the proper values of systolic and diastolic blood pressure was detected in 5\% of oncologists. The average dynamic pressure, which is a fairly constant value in case of normal regulation of blood circulation, turned out to be higher in $75 \%$ of the subjects than the standard value.

The results of changes in the indicators of cardiac activity (the second type of indicators) are presented in Fig. 2. 


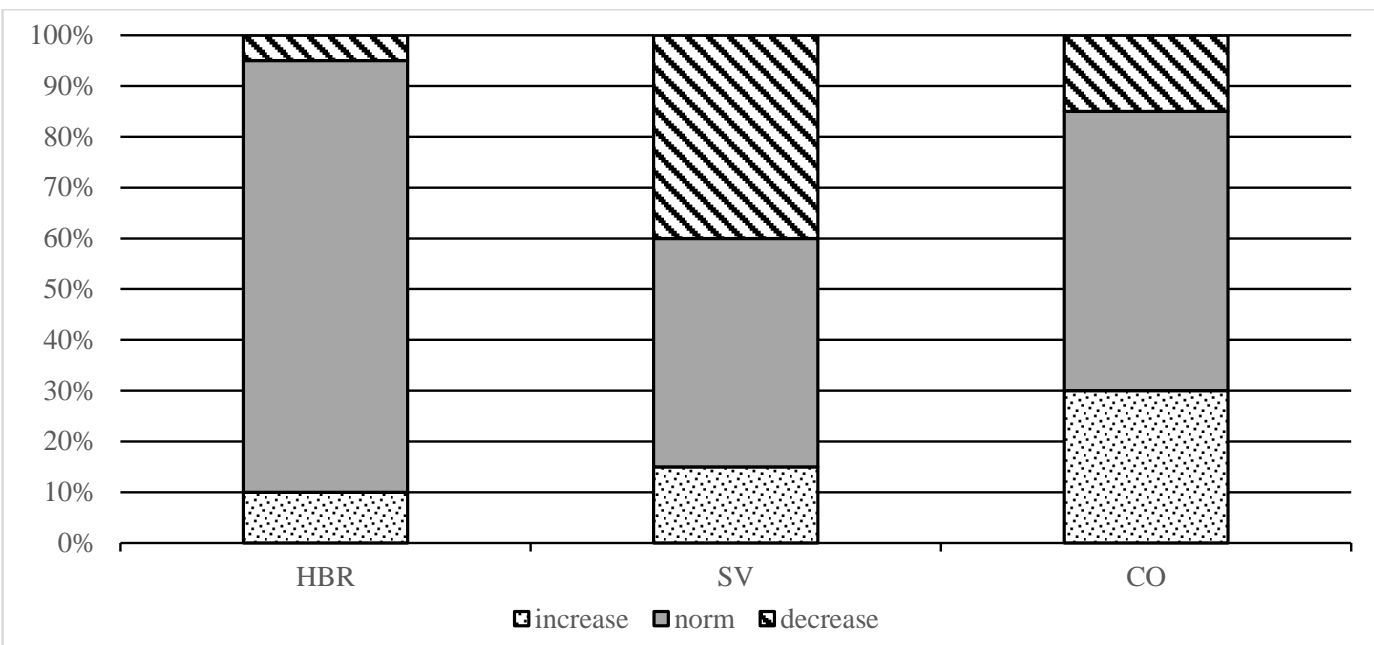

Figure 2. Subjects' cardiac function indicators in relation to the proper values, $\%$.

As seen in Fig. 2, 10\% of oncologists had tachycardia, the rest of the examined persons had heart rate within the range of standard values, and 5\% had a tendency to bradycardia. The data presented in Fig. 2 indicate a significant number of persons with low indicators of SV (40\%) and CO (30\%) among the examined doctors. This indicates that they have a reduced contractility of the myocardium and is a sign indicating a weakening of the regulatory mechanisms of hemodynamics.

The analysis of the results of studying vasculature tone indicators (third group) is shown in Fig. 3.

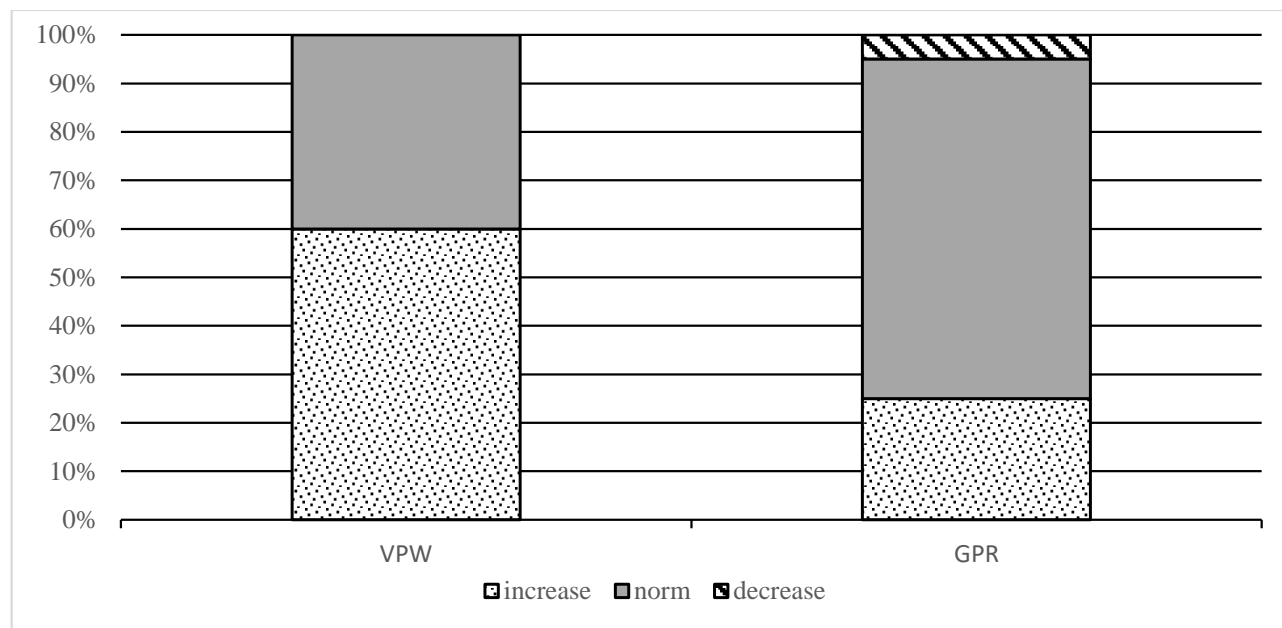

Figure 3. Indicators of subjects' vasculature tone in relation to the proper values, in $\%$.

As seen in Fig. 3, 60\% of oncologists showed an excess of the proper values of pulse ware velocity through the vessels of the elastic type. A quarter $(25 \%)$ of oncologists have an excess of values of indicators of general peripheral resistance.

In this case, the analysis of the hemodynamics types showed that the normokinetic type was found in $45 \%$, the hyperkinetic type - in $15 \%$ of the subjects. It is noteworthy that $40 \%$ of oncologists have the least optimal, hypokinetic type of hemodynamic regulation.

The results for the analysis of integral indicators of the adaptation level showed that the proportion of doctors without professional maladaptation in terms of psychophysiological indicators, in general, depending on the criterion used, ranges from $31.3 \%$ to $68.4 \%$ of the subjects (Fig. 4.). 

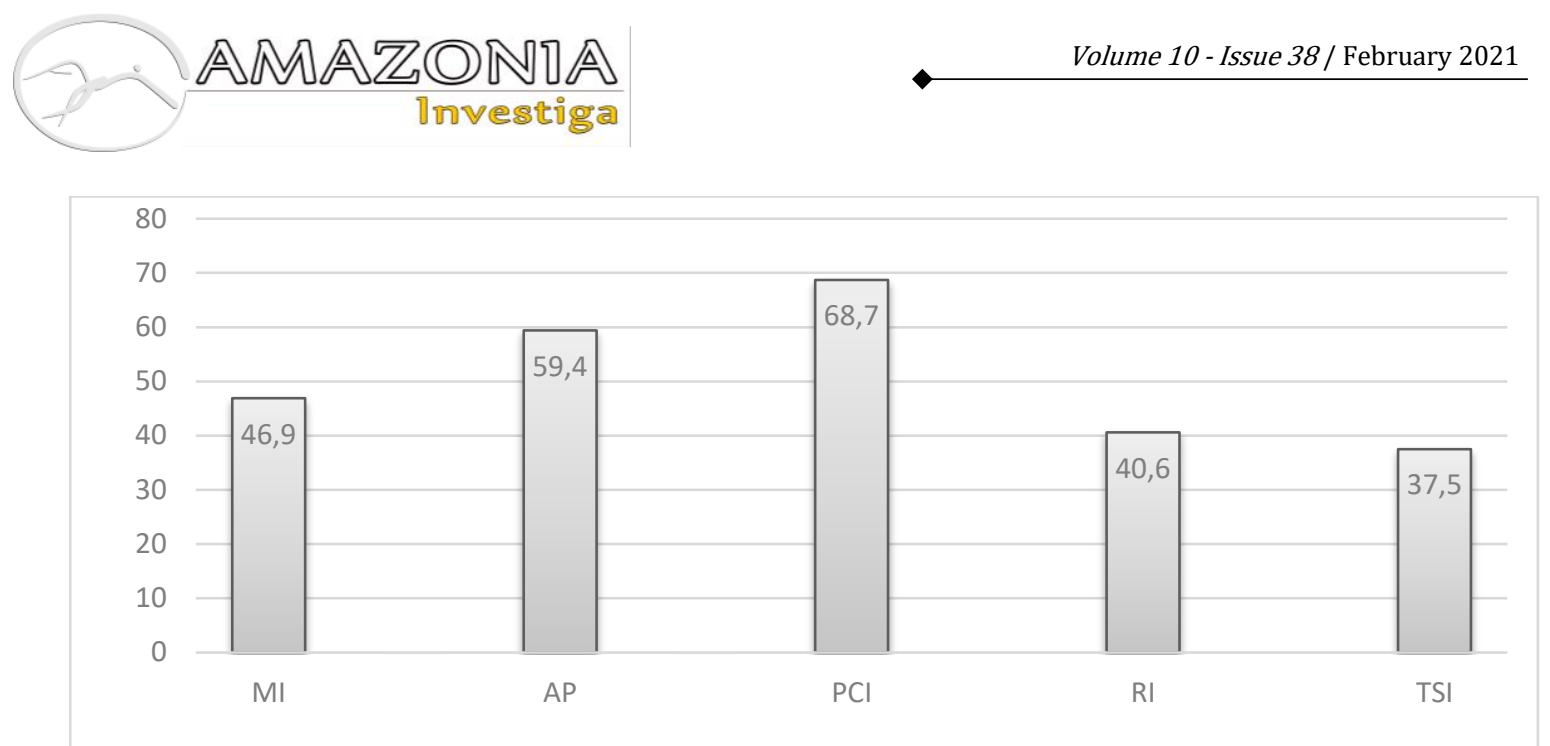

Figure 4. The share of doctors without maladaptation in terms of psychophysiological indicators, in $\%$.

Pursuant to the data in Fig. 4, for the most part, in terms of psychophysiological criteria, the oncological hospital specialists are in a state of professional maladaptation, most pronounced according to the criteria of the Myznikov index (2008), Robinson index (1967), Sheikh-Zada index (Sheikh-Zade Yu. and SheikhZade K., 2000) of the level of stress tested.

Limitations and Suggestions for Further Research. Based on the results of this study, it is possible to establish causal relationships. The study was conducted on the basis of an oncological hospital. As integral indicators of the dynamics of the level of adaptation, worlwide calculated indices were used, mainly CBT - Cognitive-Behavioral Therapy' assessments, PSS - The Perceived Stress Scale, MIES - Moral Injury Events Scale and ProQOL - Professional Quality of Life Scale Scores. Finally, future research could track the degree of relationship between occupational quality of life indicators and include other variables such as hours worked, years of practice and type of workplace conditions. Additional areas of research may include longitudinal research that investigates the effectiveness of acceptance and adherence therapy and adaptive disclosure of burnout in health care providers during work.

The main parameters featuring the state of systemic hemodynamics of the subjects indicate the tension in functioning the regulatory mechanisms of the circulatory system. Thus, against the background of normal values of systolic and diastolic blood pressure, as seen in Fig. 1, a significant number (75\%) of oncologists, has the mean blood pressure reflecting the energy of continuous blood flow exceeding the required values. Considering the fact that according to the standard value, the mean blood pressure is a fairly constant value, this may be the first and only sign for the beginning of the arterial hypertension development. The value of the mean dynamic blood pressure is proportional to the peripheral resistance and the cardiac output circulation. In this regard, the attention is drawn to the presence of a significant number of persons with low rates of SV $(40 \%)$ and $\mathrm{CO}(30 \%)$ among the examined doctors. This indicates that they have a reduced contractility of the myocardium and is a sign indicating a weakening of the regulatory mechanisms of hemodynamics. Against this background, the vasculature tone indicators, namely, a pronounced tendency to increasing the peripheral resistance, $25 \%$ of the subjects have those ones exceeding the standard values, as well as the increased velocity of pulse wave velocity through the vessels of the elastic type revealed in the most part of the examined doctors $(60 \%)$, is indicative of an increase in their tone, the presence of tension in the cardiovascular system functioning under the influence of their fulfillment of the professional activity tasks.

Consideration of integral assessments of the cardiovascular system adaptation level among the doctors of the oncological hospital, primarily the Myznikov index (MI), by the change value in which it is possible to indirectly judge the level of oxygen consumption by the body, made it possible to determine the presence of a certain decrease in the level of their adaptation during their professional activity. The satisfactory functional activity being within the range of normal reactions was found in less than half of the study participants $(49.6 \%)$. A significant number of oncologists $(40.7 \%)$ has showed the results indicating a decrease in functional activity, the rest $(12.6 \%)$ are within the zone of functional reactivation by the type of hyperreaction. 
Based on the analysis of the results for determining the PCI index according to E.A. Pirogova et al. (1986), reflecting both the level of general physical performance capacity and the state, first of all, of the cardiovascular system of the subject's body, as well as the general functional reserves of life-supporting organs and systems in general, it is defined as low and below the mean for $31.3 \%$ of specialists of the oncological dispensary. Such PCI values (50-75\% of the proper value) can be determined as corresponding to the reduced values of physical performance capacity, which is a borderline case between the standard value and pathology. At rest, no deviations from the physiological standard of such subjects are observed, however, even with small physical and psychoemotional loads, various violations can be detected (Baevsky et al., 2015).

Adaptive potential of the blood circulatory system, as a complex index calculated based on the regressive relationships of a number of indicators that play a leading role in development, maintaining the level of body adaptation to various, including occupational influence of the environment such as heart rate, blood pressure indicators, height, age and body weight of the subject; according to numerous data, it characterizes the adaptation level in general, especially during assessment and dynamic observation (Baevsky and Berseneva, 2017). The studies have shown that its values for $40.6 \%$ of specialists are within the zone of functional tension of adaptive mechanisms, which indicates a decrease in their potentials to provide equilibration with the environment, reduction of the range of mobilization reserves of the body's functioning with a sufficiently high degree of tension of the mechanisms that regulate the adaptive body reactions.

The data of the results analysis for determining the values of the Robinson index indicate that $59.4 \%$ of oncologists are within the range of preclinical and pathological conditions according to this indicator. These values of the Robinson index indicate both vascular disorder regulation and a decrease in the level of body metabolic-energy processes.

The analysis of the data for determining the calculated level of the tested stress according to Y.R. Sheikh-Zade (2000) has showed that only 37.5\% of doctors from the oncological hospital are adequately adapted to the situation when they perform their professional duties, showing the TSI values within the range of standard values of the tested stress. A significant tension in the mechanisms of adaptation to stressful environmental factors was revealed in $34.4 \%$ of the subjects who, judging by the results of the survey, suffer severe stress and various manifestations of professional maladaptation are possible.

Clinical application of the results. The data obtained as a result of research on the state of functional tone of the heart - it is possible to use the values of complex physiological indices that reflect the psychophysiological risk factors for the development of maladaptation manifestations for more accurate diagnosis of the syndrome of professional maladaptation of doctors, as an argument and evidence base for the need to take measures to optimize the functional state of the circulatory system when drawing up and conducting targeted recovery programs for oncological doctors to prevent manifestations of professional deformation (Farber, 2000).

Recommendations for mental health professionals. Mental health professionals who provide services to health care providers must distinguish between burnout and mental harm, as each term has a unique meaning for treatment. While burnout can be associated with scarcity, moral harm can convey a holistic worldview that recognizes patients' needs but cannot heal because of obstacles out of control. Workers under stress may be at greater risk of moral harm when they feel deprived of support and the psychological consequences of medical decisions. When stress occurs concurrently with exposure to other traumatic stressors, clinicians should support front-line health workers and consider the link between traumatic stress and mental harm (Oosterholt et al, 2012; Maslach and Leiter, 2008).

Cognitive-behavioral interventions can be helpful for health care professionals that validate experiences of stress and the lacking of underlying cognitive biases. For example, clinicians can be encouraged to use more adaptive and compassionate thought processes. Compassionate meditation empowers people to release harmful emotions (such as anger, shame, guilt, and suffering) by developing compassion for themselves, others, and the world. Existing research suggests that mindfulness or compassionate interventions are effective in relieving symptoms of traumatic stress.

Cognitive behavioral therapy and mindfulness-based interventions have been recommended by the Accreditation Council of Postgraduate Medical Education for residents to help manage the harmful effects 
of stress and improve hospital productivity. Clinicians should offer flexible working hours to provide injury counseling services to medical professionals who work in the hospital in the second and third shifts. Clinicians can offer alternative health care services that include short check-ups, breathing exercises, and coping with survival skills to support health care professionals after a mental health event (Grensman et al, 2018).

\section{Conclusions}

Thus, the performed studies have revealed a significant number of oncologists with reduced adaptive capabilities of the blood circulatory system. The increased values of mean arterial pressure (for $75 \%$ ), great vessels tone (for 60\%) and peripheral resistance (for 25\%) indicate a decrease in its adaptive potential and are accompanied by forming regulatory mechanisms of the circulatory function according to the hypokinetic type (for $40 \%$ of persons).

The indices that integrally characterize the functional state of the body indicate that a significant part of the specialists from the oncological hospital according to psychophysiological criteria, are in a state of professional maladaptation.

It is obvious that the current system for organizing the professional activities of medical staff of the oncological hospital can be not only the cause of the formation of psychological components of professional deformation as an emotional burnout syndrome, as it is rightly noted in various numerous studies, and also play an important role, first of all, in reducing psychophysiological and physiological indicators of professional adaptation. Therefore, complex social-psychological diagnostic examinations of doctors shall be supplemented with the studies of the functional tone of the cardiovascular system, the determination of complex physiological indices reflecting psychophysiological risk factors for the development of maladaptation manifestations that will make it possible to more accurately diagnose the syndrome of professional maladaptation.

The obtained results of the study contribute to solving one of the relevant scientific and practical problems of preventive medicine, namely, the problem of a comprehensive assessment of the psychophysiological factors of adaptation of specialists of caring professions (for example, oncologists) in order to individualize their medical and psychological support and to maintain professional health and macrobiosis.

The changes in the cardiovascular system intensity found as a result of the work under the influence of professional stressors of the labor activity of doctors from the oncological hospital will help to better reveal the clinical and psychophysiological features of the pathogenesis of maladaptation and the mechanism of the formation of one or another form of maladaptation manifestation in occupational deformation of this specialists contingent.

\section{Bibliographic references}

Akman, O., Ozturk, C., Bektas, M., Ayar, D., \& Armstrong, M.A. (2016). Job satisfaction and burnout among paediatric nurses. Journal of Nursing Management, 24(7), 923-933.

Baevsky, R.M., \& Berseneva, A.P. (2011). Introduction to prenosological diagnostics. Moscow: Slovo, 228.

Baevsky, R.M., Berseneva, A.P., Baevsky, P.A., \& Master, M. (2015). Application of principles of space medicine to health monitoring of the aging population. Cardiometry, 6, 22-29.

Baevsky, R.M., \& Berseneva, A.P. (2017). Pre-nosology diagnostics. Cardiometry, 10, 55-63.

Banerjee, S. (2019). Reply to 'physician burnout: Let's avoid unsubstantiated claims'. Nature Reviews Clinical Oncology, 16(2), 137.

Berniell, I., \& Bietenbeck, J. (2020). The effect of working hours on health. Economics \& Human Biology, 39, 100901.

Black, S.E., Devereux, P.J., \& Salvanes, K.G. (2015). Losing heart? The effect of job displacement on health. ILR Review, 68(4), 833-861.

Britt, H.R., Koranne, R., \& Rockwood, T. (2017). Statewide improvement approach to clinician burnout: Findings from the baseline year. Burnout Research, 7, 29-35.

Consoli, S.M. (2015). Occupational stress and myocardial infarction. La Presse Médicale, 44(7-8), $745-751$. 
Corrigan, L., O’Leary, C., Kroes, J., Farooq, A.R., Horgan, A., Calvert, P., \& O’Connor, M. (2019). Professional burnout, work patterns and career satisfaction in medical oncologists in Ireland. Irish Journal of Medical Science, 189(2): 711-718.

Crane, M.F., Kho, M., Kangas, M., Griffin, B., Karin, E., Earl, J., \& Harris, C. (2020). Strengthening resilience in over 50's: A nested clustered-randomized controlled trial of adaptive systematic self-reflection. Anxiety Stress, and Coping, 33(6), 623-641.

Edwards, N., Kornacki, M.J., \& Silversin, J. (2002). Unhappy doctors: What are the causes and what can be done? BMJ, 324(7341), 835-838.

Farber, B.A. (2000). Treatment strategies for different types of teacher burnout. Journal of Clinical Psychology, 56(5), 675-689.

Fernández-Sánchez, J.C., Pérez-Mármol, J.M., Santos-Ruiz, A.M., Pérez-García, M., \& Peralta-Ramírez, M.I. (2018). Burnout and executive functions in palliative care health professionals: Influence of burnout on decision making. Anales del Sistema Sanitario de Navarra, 41(2), 171-180.

Freudenberger, H.J. (1974). Staff burnout. Journal of Social Issues, 30(1), 159-165.

Gardner, R.L., Cooper, E., Haskell, J., Harris, D.A., Poplau, S., Kroth, P.J., \& Linzer, M. (2019). Physician stress and burnout: The impact of health information technology. Journal of the American Medical Informatics Association, 26(2), 106-114.

Gômez-Urquiza, J.L., Monsalve-Reyes, C.S., San Luis-Costas, C., Fernández-Castillo, R., Aguayo-Estremera, R., \& Cañadas-de la Fuente, G.A. (2017). Risk factors and burnout levels in Primary Care nurses: A systematic review. Aten Primaria, 49(2), 77-85.

Grensman, A., Acharya, B., Wändell, P., Nilsson, G., Falkenberg, T., Sundin, Ö., \& Werner, S. (2018). Effect of traditional yoga, mindfulness-based cognitive therapy, and cognitive behavioral therapy, on health related quality of life: A randomized controlled trial on patients on sick leave because of burnout. BMC Complementary and Alternative Medicine, 18(1), 80.

Hariharan, T.S., \& Griffin, B. (2019). A review of the factors related to burnout at the early-career stage of medicine. Medical Teacher, 41(12), 1380-1391.

Harma, M.I. (2003). Are long workhours a health risk? Scandinavian Journal of Work Environment \& Health, 29(3), 167-169.

Lee, F.J., Stewart, M., \& Brown, J.B. (2008). Stress, burnout, and strategies for reducing them: What's the situation among Canadian family physicians? Canadian Family Physician, 54(2), 234-235.

Maslach, C., \& Leiter, M. (2008). The Truth About Burnout: How Organizations Cause Personal Stress and What to Do About It. Hoboken, NJ: John Wiley \& Sons.

Maslach, C., Leiter, M., \& Jackson, S. (2018). MBI: The Maslach Burnout Inventory Manual. 4th edn. Menlo Park: Mind Garden, Inc.

Maslach, C., Schaufeli, W.B., \& Leiter, M.P. (2001). Job burnout. Annual Review of Psychology, 52, 397-422.

Medscape. (2020). Medscape National Physician Burnout \& Suicide Report 2020. https://www.medscape.com/slideshow/2020-lifestyle-burnout-6012460? faf =1\#2 (Accessed 25.03.2021)

Murali, K., \& Banerjee, S. (2018). Burnout in oncologists is a serious issue: What can we do about it? Cancer Treatment Reviews, 68, 55-61.

Murali, K., \& Banerjee, S. (2019). Let's address burnout in oncologists and reimagine the way we work. Nature Reviews Clinical Oncology, 16(1), 1-2.

Myznikov, I.L., Gliko, L.I., \& Payusov, Y.A. (2008). Methodology for Monitoring the Functional State of Seafarers. Diagnostic Indices and Physiological Stress Tests. Murmansk: Sever.

Oosterholt, B.G., Van der Linden, D., Maes, J.H., Verbraak, M.J., \& Kompier, M.A. (2012). Burned out cognition - cognitive functioning of burnout patients before and after a period with psychological treatment. Scandinavian Journal of Work, Environment \& Health, 38(4), 358-369.

Pirogova, E.A., Ivashchenko, L.Y., \& Strapko, N.P. (1986). The Influence of Physical Activity on Performance and Human Health. Kiev: Health.

https://spblib.ru/en/catalog/-/books/3358741-vlianie-fiziceskih-upraznenij-na-rabotosposobnost-i-zdorove-celoveka; http://library.ngmu.ru/search/view?mfn=15872\&irbisBase=WORK2

Raphael, M.J., Fundytus, A., Hopman, W.M., Vanderpuye, V., Seruga, B., Lopes, G., Hammad, N., Sengar, M., Brundage, M.D., \& Sullivan, R. (2019). Medical oncology job satisfaction: Results of a global survey. Seminars in Oncology, 46(1), 73-82.

Robinson, B.F. (1967). Relation of heart rate and systolic blood pressure to the onset ofpain in angina pectoris. Circulation, 35(1), 1073-1083.

Sheikh-Zade, Y.R., \& Sheikh-Zade, K.Y. (2000). The way to determine the level of stress (patent). Inventions. Utility models, 12, 2147831. 
Stucky, E.R., Dresselhaus, T.R., Dollarhide, A., Shively, M., Maynard, G., Jain, S., Wolfson, T., Weinger, M.B., \& Rutledge, T. (2009). Intern to attending: Assessing stress among physicians. Academic Medicine, 84(2), 251-257.

Swetz, K.M., Harrington, S.E., Matsuyama, R.K., Shanafelt, T., \& Lyckholm, L. (2009). Strategies for avoiding burnout in hospice and palliative medicine: Peer advice for physicians on achieving longevity and fulfillment. Journal of Palliative Medicine, 12(9), 773-777.

Tilett, R. (2003). The Patient within - Psychopathology in the Helping Professions. Advances in Psychiatric Treatment, 9(4), 272-279.

Toker, S., Melamed, S., Berliner, S., Zeltser, D., \& Shapira, I. (2012). Burnout and risk of coronary heart disease: A prospective study of 8838 employees. Psychosomatic Medicine, 74(8), 840-847.

Van Dam, A., Keijsers, G., Verbraak, M., Eling, P., \& Becker, E. (2015). Level and appraisal of fatigue are not specific in burnout. Clinical Psychology \& Psychotherapy, 22(2), 133-141.

Van der Hulst, M. (2003). Long workhours and health. Scandinavian Journal of Work Environment \& Health, 29(3), 171-188.

White, C. (2002). Doctors under fire. BMJ, 324(7328), 55.

Williams, B. (2002). Physician stress \& burnout. Tennessee Medicine: Journal of the Tennessee Medical Association, 95(11), 445-51.

Yates, S.W. (2020). Physician stress and burnout. The American Journal of Medicine, 133(2), 160-164.

Yates, M., \& Samuel, V. (2019). Burnout in oncologists and associated factors: A systematic literature review and meta-analysis. European Journal of Cancer Care, 28(3), e13094.

Zasyadko, K.I. (2019). The psychological and psychophysiological issues of professional maladaptation of oncologists. Journal of Human Sport and Exercise, 14(5proc), 2339-2348. 